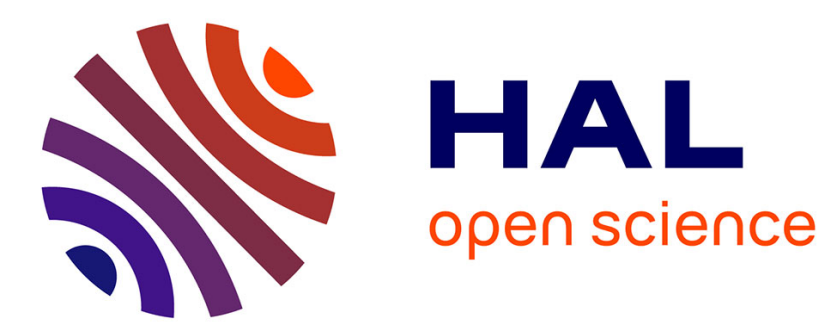

\title{
A Confirmatory Analysis of the Unit Root Hypothesis for OECD Consumption-Income Ratios
}

Diego Romero-Avila

\section{To cite this version:}

Diego Romero-Avila. A Confirmatory Analysis of the Unit Root Hypothesis for OECD ConsumptionIncome Ratios. Applied Economics, 2008, 40 (17), pp.2271-2278. 10.1080/00036840600949447 . hal00582089

\section{HAL Id: hal-00582089 \\ https://hal.science/hal-00582089}

Submitted on 1 Apr 2011

HAL is a multi-disciplinary open access archive for the deposit and dissemination of scientific research documents, whether they are published or not. The documents may come from teaching and research institutions in France or abroad, or from public or private research centers.
L'archive ouverte pluridisciplinaire HAL, est destinée au dépôt et à la diffusion de documents scientifiques de niveau recherche, publiés ou non, émanant des établissements d'enseignement et de recherche français ou étrangers, des laboratoires publics ou privés. 


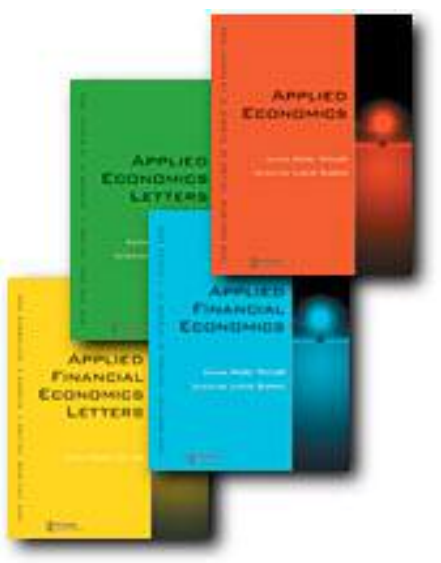

\section{A Confirmatory Analysis of the Unit Root Hypothesis for OECD Consumption-Income Ratios}

\begin{tabular}{|r|l|}
\hline Journal: & Applied Economics \\
\hline Manuscript ID: & APE-06-0147.R1 \\
\hline Journal Selection: & Applied Economics \\
\hline JEL Code: & $\begin{array}{l}\text { C15 - Statistical Simulation Methods|Monte Carlo Methods < C1 - } \\
\text { Econometric and Statistical Methods: General < C - Mathematical } \\
\text { Consumption, Saving, Production, Employment, and Investment }< \\
\text { E - Macroeconomics and Monetary Economics, C23 - Models with } \\
\text { Panel Data < C2 - Econometric Methods: Single Equation Models < } \\
\text { C - Mathematical and Quantitative Methods }\end{array}$ \\
\hline Keywords: & Consumption, Unit Root, Cross-Dependence, Bootstrap Distribution \\
\hline \hline
\end{tabular}

powered by ScholarOne

\section{Manuscript Central ${ }^{\mathrm{TH}}$}




\title{
A Confirmatory Analysis of the Unit Root Hypothesis for OECD Consumption-Income Ratios
}

\begin{abstract}
This paper investigates the existence of a unit root in the consumption-income ratio for a sample of 23 OECD countries over the period 1960-2005. For that purpose, we first use recently developed unit root tests with good size and power. Second, we employ the more powerful panel unit root tests of Smith et al. (2004) and Pesaran (2003) that take the null of nonstationarity and a bootstrap version of the test of Hadri (2000) that takes stationarity as the null hypothesis. Overall, our confirmatory analysis renders clear-cut evidence that OECD consumption-income ratios contain a unit root.
\end{abstract}

JEL classification: E21, C15, C23

Key words: Consumption, Panel Unit Root Testing, Cross-sectional Dependence, Bootstrap Distribution. 


\section{Introduction}

The examination of the presence of stochastic trends in macroeconomic variables has drawn considerable attention among macroeconomists since the seminal work of Nelson and Plosser (1982). The distinction between stochastic and deterministic trends in a macroeconomic series is crucial for understanding the nature of shocks. So if a series contains a unit root, the variable is path-dependent as its current value heavily depends on past levels. In this case, temporary shocks affect the variable permanently as the effect accumulates over time. In contrast, if a series is stationary, temporary shocks can at most have long-lasting but not permanent effects, since the effect vanishes as time elapses.

In this paper, we investigate the existence of a unit root in the consumptionincome ratio -also known as average propensity to consume (APC)- for a sample of 23 OECD countries over the period 1960-2005. The presence of a unit root in APC carries important implications with regard to the empirical validity of some theoretical hypotheses on consumption behaviour and the econometric modelling of consumption functions. As noted by Sarantis and Stewart (1999), a unit root in APC would be congruent with the Keynesian absolute income hypothesis, Deaton's (1977) involuntary savings theory and the Marxian undercompensating theory. That would support the lack of mean reversion in APC towards a steady state level in response to shocks. In contrast, Duesenberry's (1952) relative income hypothesis, Friedman's (1957) permanent income hypothesis and Ando-Modigliani's (1963) life-cycle hypothesis imply that APC is best described as stationary in the long-run. As a result, they predict the existence of a long-run equilibrium relationship between consumption and income, thus leading the consumption-income ratio to converge to a steady-state level. In addition, the great-ratios literature predicts the 
existence in the long-run of stationary investment-income and consumption-income ratios along the balanced growth path. ${ }^{1}$

These theoretical implications have not gone untested. Early studies using conventional unit root tests of the augmented Dickey-Fuller (1979, ADF) type provided evidence supporting the presence of a unit root in APC. These include Drobny and Hall (1989), Hall and Patterson (1992), Molana (1991), Horioka (1997), Bjornland (1999) and Cook (2003). ${ }^{2}$ In contrast, we also find a series of studies providing some evidence in favour of stationarity in APC. These include Campbell (1987), Lettau and Ludvigson (2001), Slesnick (1998) and UrgernSternberg (1986). More recently, two studies -Sarantis and Stewart (1999) and Jin (1995)- have argued that the conflicting evidence obtained in the literature may be the result of the low power of conventional univariate unit root tests when confronted with small data samples and near unit-root processes (see Campbell and Perron, 1991; DeJong et al., 1992). In response, they employ panel unit root tests which exploit the cross-sectional variability of the data, thus rendering important gains in power. Jin (1995) applies the test of Levin et al. (2002, LLC hereafter) to a sample of twelve OECD countries over the period 1960-1988. He finds evidence of cointegration between nonstationary income and consumption levels, thus implying stationarity in OECD consumption-income ratios. Sarantis and Stewart (1999) employ the panel unit root tests of Im et al. (2003, IPS hereafter) and Taylor and Sarno (1988). Their evidence from conventional ADF tests and the two panel unit

\footnotetext{
${ }^{1}$ The analysis at the univariate level of the degree of persistence in consumption-income ratios has not been confined to distinguishing between stationarity and a unit root process. One possible alternative comprises the use of fractional integration techniques. Using fractionally based tests, GilAlana and Robinson (2001) find that consumption-income ratios for the UK and Japan can be best characterised by seasonal fractional integration with amplitudes varying across frequencies.

${ }^{2}$ Within the great-ratios literature, Serletis and Krichel (1995), Hossain and Chung (1999), Harvey et al. (2003) provide very little evidence of stationary consumption-income ratios for several industrialised countries.
} 
root tests point to the presence of a unit root in APC for 20 OECD countries over the period 1955-1994.

In this paper we re-examine the stochastic properties of OECD consumptionincome ratios. For that purpose, we conduct unit root testing and take two alternative paths to increase statistical power. First, we use the univariate unit root tests of $\mathrm{Ng}$ and Perron (2001) which modify conventional unit root tests through a local-to-unity framework in order to render tests with good size and power properties. The use of these tests allows us to be more confident that failures to reject the null of a unit root are not caused by low statistical power, while rejections are not due to size distortions caused by the presence of a large moving average root in the series (see Perron and $\mathrm{Ng}, 1996$ ). For confirmatory purposes, we also compute the univariate stationarity test of Kwiatkowski et al. (1992, KPSS hereafter). Secondly, we deploy panel stationarity and unit root tests which increase power by exploiting the cross-sectional variation of the data. In doing so, we take account of a major caveat applying to the panel unit root tests employed by Sarantis and Stewart (1999) and Jin (1995), i.e. the failure to control for error cross-sectional dependence which leads the tests to exhibit severe size distortions. Some studies documenting spurious rejections of the null hypothesis from panel tests that assume cross-sectional independence include O’Connell (1998), Maddala and Wu (1999), Strauss and Yigit (2003) and Banerjee et al. (2005). Therefore, we employ the stateof-the-art panel unit root tests of Smith et al. (2004) and Pesaran (2003) which explicitly allow for error cross-sectional correlation. Smith et al. (2004) control for it through modified bootstrap methods while Pesaran (2003) does so by augmenting standard ADF specifications with cross-sectional averages of lagged levels and first-differences of the underlying series. 
Since most of the existing panel unit root tests -including the ones employed in our analysis- are constructed in a way that rejection of the null hypothesis of joint nonstationarity tells us only that some but not all cross-sectional units are stationary, it is advisable to complement that analysis with panel tests that take joint stationarity as the null hypothesis. Therefore, as noted by Shin and Snell (2006), by using panel unit root tests jointly with panel stationarity tests, we may be able to draw definitive conclusions about the stochastic properties of the variable under consideration. In fact, rejection in both panel unit root and stationarity tests would indicate the existence of a mixture of stationarity and nonstationarity in the panel, while failure to reject the null in both tests could lead to inconclusive inferences. In addition, there are two cases leading to definitive conclusions: 1) when there is rejection of the null with the panel stationarity test but not with the panel unit root test, which implies that all cross-sectional units contain a unit root, and 2) when there is rejection with the panel unit root test but not with the panel stationarity test, which points to stationarity in all cross-sectional units.

Therefore, to conduct a confirmatory analysis we complement the use of panel unit root tests with the panel stationarity test proposed by Hadri (2000) which is computed as an average of individual KPSS tests. Since the asymptotic distribution of Hadri's test assumes cross-sectional independence, we allow for general forms of cross-sectional dependence by simulating the bootstrap distribution of Hadri's test following Maddala and $\mathrm{Wu}$ (1999). Overall, our confirmatory analysis provides clear-cut support for the existence of a unit root in OECD consumption-income ratios over the post-war era.

The remainder of the paper is structured as follows. Section 2 describes the data and the procedures employed in the analysis for the conduct of unit root testing. 
Section 3 presents the results of the analysis of the stochastic properties of OECD consumption-income ratios through unit root testing and Section 4 summarises the main findings and then concludes.

\section{Data and Methodology}

\subsection{Data Description}

We employ annual data on the consumption-income ratio for 23 OECD countries over the period 1960-2005. The consumption-income ratios are computed as the ratio of total private consumer's expenditure measured at 2000 prices over total GDP at 2000 prices. The ratio is expressed in natural logs. The primary source of the data is the OECD Economic Outlook, No. 78. The list of OECD countries analysed includes: Australia, Austria, Belgium, Canada, Switzerland, Germany, Denmark, Spain, Finland, France, United Kingdom, Greece, Ireland, Iceland, Italy, Japan, Luxembourg, Netherlands, Norway, New Zealand, Portugal, Sweden and United States.

\subsection{Econometric Methodology}

\section{Univariate unit root tests with good size and power}

In order to conduct unit root testing at the univariate level, we employ the $M^{G L S}$ class of tests with good size and power proposed by Ng and Perron (2001) and the $A D F^{G L S}$ test first proposed by Elliot et al. (1996). All these tests apply local-tounity Generalised Least Squares (GLS) detrending in order to gain power. The $A D F^{G L S}$ test is the t-statistic for testing the existence of a unit root with a specification where the underlying series is detrended with GLS prior to estimation by OLS. The $M^{G L S}$ class of tests includes $M Z_{\alpha}^{G L S}$ and $M Z_{t}^{G L S}$ which are modified versions of the $Z_{\alpha}$ and $Z_{t}$ Phillips-Perron (1988) tests, $M S B^{G L S}$ which is a 
modified version of the Sargan and Bhargava (1983) test, and the feasible point optimal test $\left(P_{T}^{G L S}\right)$.

For these tests to exhibit good size properties, it is crucial to select the appropriate lag truncation $(k)$ of the ADF specification. For that purpose, $\mathrm{Ng}$ and Perron (2001) develop the modified Akaike information criterion (MAIC) which aims at selecting a relatively long lag-length in the presence of a large negative moving average root (thus preventing size distortions) and a short lag-length when that root is not present (thus avoiding unnecessary loss of power). In our application, we take a maximum lag truncation equal to 8 .

\section{Panel unit root and stationarity tests with cross-sectional dependence}

Smith et al. (2004) have developed more powerful variants of some commonly used panel unit root tests, thereby allowing for general forms of cross-sectional dependence through bootstrap methods. The first two tests are the standard IPS tests. The t-bar statistic is computed as an average of individual t-statistics from ADF specifications, i.e. $\bar{t}_{N T}=N^{-1} \sum_{i=1}^{N} t_{i}$, where $i=1, \ldots \ldots, N$ and $t=1, \ldots \ldots, T$ stand for the number of panel members and time periods, respectively. The standardised statistic is given by:

$$
\Psi_{\bar{t}}=\frac{\sqrt{N}\left(\bar{t}_{N T}-E\left(t_{i}\right)\right)}{\sqrt{\operatorname{Var}\left(t_{i}\right)}}
$$

where $E\left(t_{i}\right)$ and $\operatorname{Var}\left(t_{i}\right)$ are the expected value of the mean and variance, respectively. IPS also proposed the Lagrange Multiplier (LM) test statistic, which after normalisation takes the form:

$$
\Psi_{L M}=\frac{\sqrt{N}\left(L M_{N T}-E\left(L M_{i}\right)\right)}{\sqrt{\operatorname{Var}\left(L M_{i}\right)}}
$$

where $L M_{i}$ is the individual $L M$ test and $L M_{N T}=N^{-1} \sum_{i=1}^{N} L M_{i}$. Smith et al. (2004) also develop panel versions of some powerful modifications of univariate 
ADF t-statistics such as the Max test $\left(\operatorname{Max}_{i}\right)$ which is based on forward and reverse ADF regressions:

$$
\Psi_{\operatorname{Max}}=\frac{\sqrt{N}\left(\operatorname{Max}_{N T}-E\left(\operatorname{Max}_{i}\right)\right)}{\sqrt{\operatorname{Var}\left(\operatorname{Max}_{i}\right)}}
$$

where $\operatorname{Max}_{N T}=N^{-1} \sum_{i=1}^{N} \operatorname{Max}_{i}$, the weighted symmetric test $\left(W S_{i}\right)$ :

$$
\Psi_{W S}=\frac{\sqrt{N}\left(W S_{N T}-E\left(W S_{i}\right)\right)}{\sqrt{\operatorname{Var}\left(W S_{i}\right)}}
$$

where $W S_{N T}=N^{-1} \sum_{i=1}^{N} W S_{i}$, and the minimum LM statistic $\left(\operatorname{Min}_{i}\right)$ which is also based on forward and reverse ADF regressions:

$$
\Psi_{M i n}=\frac{\sqrt{N}\left(\operatorname{Min}_{N T}-E\left(\operatorname{Min}_{i}\right)\right)}{\sqrt{\operatorname{Var}\left(\operatorname{Min}_{i}\right)}}
$$

where $\operatorname{Min}_{N T}=N^{-1} \sum_{i=1}^{N} \operatorname{Min}_{i}$. Since all of these tests assume both cross-sectional independence and asymptotic normality, Smith et al. (2004) develop a modified bootstrap procedure to compute $\mathrm{p}$-values of the statistics which are robust to smallsample bias and to cross-sectional dependencies in the data. ${ }^{3} \Psi_{\bar{t}}, \Psi_{M a x}$ and $\Psi_{W S}$ reject the null hypothesis for large negative values of the statistic, while $\Psi_{L M}$ and $\Psi_{\text {Min }}$ reject the null for large positive values. ${ }^{4}$

Pesaran (2003) models cross-sectional correlation using a one-factor model given by $u_{i t}=\gamma_{i} f_{t}+\varepsilon_{i t}$, where $f_{t}$ is the unobserved common factor, $\gamma_{i}$ is the factor loading coefficient and $\varepsilon_{i t}$ is the idiosyncratic error component. Pesaran augments standard ADF specifications with the cross-sectional averages of lagged levels and first-differences of the series in order to eliminate the cross-sectional dependence embodied in $\gamma_{i} f_{t}$. This renders cross-sectionally augmented ADF t-statistics, i.e. $C A D F_{i}$ for each $i$, which are denoted by $t_{i}(N, T)$. Pesaran (2003) constructs a

\footnotetext{
${ }^{3}$ See Smith et al. (2004, pp. 165-166) for details on the bootstrap procedure following Maddala and $\mathrm{Wu}$ (1999) which generates bootstrap innovations through resampling using a block size of 30 and 20,000 replications. The maximum lag order of autocorrelation used to compute the statistics is set at 8 .

${ }^{4}$ All the five tests take as the null hypothesis the presence of a unit root for all individuals versus the alternative of stationarity for at least one individual unit.
} 
modified version of the IPS t-bar test by averaging individual CADF statistics, rendering the cross-sectionally augmented IPS, i.e. $C I P S=N^{-1} \sum_{i=1}^{N} t_{i}(N, T)$. Pesaran also combines p-values of $C A D F_{i}$ to compute the inverse accumulated normal test $C Z=N^{-1 / 2} \sum_{i=1}^{N} \Phi^{-1}\left(p_{i T}\right)$, where $p_{i T}$ is the p-value associated with $C A D F_{i}$. Critical values are simulated for various sample sizes.

Hadri (2000) develops a panel stationarity test which is robust to the presence of autocorrelated and heteroskedastic errors. Let $\left\{y_{i, t}\right\}$ be the set of stochastic processes given by:

$$
y_{i, t}=\alpha_{i, t}+\beta_{i} t+\varepsilon_{i, t} \quad \text { and } \quad \alpha_{i, t}=\alpha_{i, t-1}+v_{i, t}
$$

where $\alpha_{i, t}$ is a random walk and $\left\{\varepsilon_{i, t}\right\}$ and $\left\{v_{i, t}\right\}$ are assumed mutually independent. The null hypothesis of stationarity implies that $\alpha_{i, t}$ collapses into a constant $\left(\sigma_{v, i}^{2}=0\right.$ for all $i$ ) versus the alternative that $\sigma_{v, i}^{2}>0$ for some $i$. Hadri (2000) computes the panel stationarity test as the average of univariate KPSS tests:

$$
\eta_{k}=N^{-1} \sum_{i=1}^{N}\left(\hat{\sigma}_{i}^{-2} T^{-2} \sum_{t=1}^{T} \hat{S}_{i, t}^{2}\right),
$$

where $\hat{\sigma}_{i}^{-2} T^{-2} \sum_{t=1}^{T} \hat{S}_{i, t}^{2}=\eta_{i}$ is the univariate KPSS test for individual $i$, and $\hat{S}_{i, t}=\sum_{j=1}^{t} \hat{\varepsilon}_{i, j}$ stands for the partial sum of the estimated OLS residuals from (6). $\hat{\sigma}_{i}^{2}$ represents a consistent estimate of the long-run variance of $\varepsilon_{i, t}$, which allows for serial correlation and heteroskedasticity across the cross-sectional dimension. ${ }^{5}$ Equation (7) allows for heterogeneity in the estimation of the long-run variances across units, but homogeneity can also be assumed by replacing $\hat{\sigma}_{i}^{2}$ in (7) with $\hat{\sigma}^{2}=N^{-1} \sum_{i=1}^{N} \hat{\sigma}_{i}^{2}$. For the sake of robustness, we compute the test under both assumptions. After standardising the test, we have

$$
L M=\frac{\sqrt{N}\left(\eta_{k}-\mu\right)}{v} \stackrel{d}{\rightarrow} N(0,1)
$$

\footnotetext{
${ }^{5}$ These are obtained non-parametrically using the quadratic spectral kernel with fixed bandwidth.
} 
where $\mu$ and $v^{2}$ are the mean and variance adjustment factors such that $\mu=1 / 6$ and $v^{2}=1 / 45$ for the specification without trends and $\mu=1 / 15$ and $v^{2}=11 / 6300$ for the specification with trends. ${ }^{6}$ The computation of Hadri's statistic requires the individual series to be cross-sectionally independent along with asymptotic normality. Since these assumptions may be overly strong, we will compute the bootstrap distribution of the panel stationarity test following Maddala and $\mathrm{Wu}$ (1999) to allow for general forms of cross-sectional dependence, thereby correcting for finite-sample bias.

\section{Empirical results}

We report in Table 1 the results of univariate unit root tests with good size and power for the specification with a linear trend since we find evidence supporting the statistical significance of the trend coefficient. Our preliminary findings point to the existence of a unit root in OECD consumption-income ratios, as we fail to reject the unit root null even at the $10 \%$ significance level for any of the twenty-three countries under analysis. ${ }^{7}$ As regards univariate KPSS tests for the specification with a linear trend - see column 8 of Table $1-$, we are unable to reject the null of stationarity at the $1 \%$ level for any country. Still, we reject the stationarity null at 5\% for Austria and Luxembourg, and at 10\% also for Australia, Switzerland, Finland, France, Italy, Japan and the Netherlands.

In all, the analysis with univariate unit root and stationarity tests renders mixed evidence regarding the order of integration of OECD consumption-income ratios: while unit root tests point to the presence of a unit root in the series, the KPSS

\footnotetext{
${ }^{6}$ Hadri's statistic must be compared with the upper tail of the standard normal distribution.

${ }^{7}$ To conserve space, we do not show the results from the computation of the univariate unit root tests by $\mathrm{Ng}$ and Perron (2001) for the specification without a linear trend. Nonetheless, the results remain fairly unchanged since we can only reject the null of a unit root at a marginal $10 \%$ level with some tests for Australia, New Zealand and Portugal. These results are available from the author upon request.
} 
stationarity test supports mainly the existence of stationarity in the series. This conflicting evidence should not come up as a surprise since it conforms well with that of early studies employing univariate tests. However, the fact that the unit root tests of Perron and $\mathrm{Ng}$ (2001) are expected to show good size and power may indicate that failure to reject the unit root null in OECD consumption-income ratios is not caused by low statistical power, but due to the presence of permanent movements in the series.

\section{[Insert Table 1 about here]}

All that said, it is widely recognised in the literature that the use of panel unit root and stationarity tests that exploit the cross-sectional variation of the data leads to a much more efficient way to achieve substantial power gains. However, one important caveat is to be considered when conducting panel unit root testing: traditional panel unit root and stationarity tests derived under the assumption of cross-sectional independence are subject to severe size distortions, which leads to spuriously over-reject the null hypothesis. As the international real business cycle literature has demonstrated, there appear to be strong linkages between macroeconomic aggregates -including consumption- among industrialised countries (see Backus et al., 1992; Devereux et al., 1992). As a result, we explicitly allow for cross-sectional dependence in the panel stationarity and unit root tests employed in the analysis.

We now proceed to present the results from the powerful unit root tests of Smith et al. (2004), which control for general forms of cross-dependence and finite-sample bias through residual-based bootstrap methods along similar lines to Maddala and $\mathrm{Wu}$ (1999). In deriving the empirical distributions of the five statistics tailored to the structure of the cross-sectional correlation of the error and to the sample size of 
our panel of OECD consumption-income ratios, we employ a block size equal to 30 and 20,000 bootstrap replications. The maximum lag-order for individual specifications is set at 8 . As reported in Table 2, all of the five tests proposed by Smith et al. (2004) are unable to reject the unit root null even at the $10 \%$ level irrespective of the inclusion of linear trends in the specification. As regards Pesaran's (2003) tests, our findings again confirm the above results, as we fail to reject the null of nonstationarity with any of the two tests regardless of the inclusion of linear trends in the specification.

\section{[Insert Table 2 about here]}

Table 3 shows the results of the panel stationarity test of Hadri (2000). Panel A reports the result of the computation of the test under the assumption of crosssectional independence and asymptotic normality, while Panel B reports the bootstrap critical values allowing for general forms of cross-sectional dependence, thereby correcting for finite-sample bias. Under the assumption of cross-sectional independence, Hadri's test strongly rejects the null of stationarity in favour of a unit root irrespective of the assumption of homogeneity or heterogeneity in the computation of the long-run variance. To deal with the issue of cross-dependence, we compute the bootstrap distribution of Hadri's test, which appears to dramatically shift to the right of the upper tail of the standard normal distribution as expected. But despite this sharp rise in the critical values, we are still able to reject the null at the $2.5 \%$ level, thus supporting the existence of a unit root in OECD consumptionincome ratios. This finding is robust to the degree of heterogeneity assumed in the estimation of the long-run variance and to the inclusion of deterministic trends in the specification.

\section{[Insert Table 3 about here]}


All in all, our thorough investigation of the stochastic properties of OECD consumption-income ratios renders consistent evidence supportive of the unit root hypothesis. This occurs in spite of attempting to raise statistical power by employing 1) univariate unit root tests with good size and power and 2) the panel unit root tests of Smith et al. (2004) and Pesaran (2003) along with the panel stationarity test of Hadri (2000), which all exploit the cross-sectional variation of the data. The fact that we obtain these results from panel unit root tests which take nonstationarity as the null as well as from the panel KPSS test which takes the null of stationarity, should make us more confident that OECD consumption-income ratios are best described as nonstationary. Our results appear to conform not only with those from early studies employing conventional unit root tests, but also with Sarantis and Stewart (1999) that employed the panel unit root tests of IPS and Taylor and Sarno (1998).

\section{Conclusions}

In this paper we have investigated the existence of a unit root in the consumption-income ratio for a sample of 23 OECD countries over the period 1960-2005. For that purpose, we have conducted unit root testing by taking two alternative avenues to raise statistical power. First, we have employed the univariate unit root tests of $\mathrm{Ng}$ and Perron (2001) which modify conventional unit root tests through GLS-detrending to yield tests with good size and power. For confirmatory purposes, we have also computed univariate KPSS tests. Second, we have deployed the panel unit root tests of Smith et al. (2004) and Pesaran (2003) and the panel stationarity test of Hadri (2000), which all increase power by exploiting the crosssectional variation of the data. All of these panel tests take account of the presence of cross-sectional correlation in the error structure of the panel. 
Overall, our examination of the stochastic properties of OECD consumptionincome ratios has yielded strong evidence for the existence of a unit root in the series. The fact that we obtain these results employing tests that 1) show good power and size properties, 2) allow for cross-sectional dependence, and 3) take nonstationarity and stationarity as null hypotheses, should make us more confident of the existence of stochastic trends in OECD consumption-income ratios. These results appear to be congruent with the Keynesian absolute income hypothesis, Deaton's involuntary savings theory and the Marxian undercompesating theory.

\section{References}

Ando, A. and Modigliani, F. (1963) The life-cycle hypothesis of saving: Aggregate implications and tests, American Economic Review, 53, 55-84.

Backus, D., Kehoe, P. and Kydland, F. (1992) International real business cycles, Journal of Political Economy, 101, 745-775.

Banerjee, A., Marcellino, M. and Osbat, C. (2005) Testing for PPP: Should we use panel methods?, Empirical Economics, 30, 77-91.

Bjornland, H.D. (1999) Structural breaks and stochastic trends in macroeconomic variables in Norway, Applied Economics Letters, 6, 133-138.

Campbell, J.Y. (1987) Does Saving anticipate declining Labor Income? An alternative test of the permanent income hypothesis, Econometrica, 55, 12491273.

Campbell, J.Y. and Perron, P. (1991) Pitfalls and opportunities: What macroeconomists should know about unit roots, NBER Macroeconomic Annual 1991, 141-201. 
Cook, S. (2003) The nonstationarity of the consumption-income ratio: Evidence from more powerful Dickey-Fuller tests, Applied Economic Letters, 10, 393-395.

Deaton, A.S. (1977) Involuntary saving through unanticipated inflation, American Economic Review, 6, 899-910.

DeJong, D.N., Nankervis, J., Savin. N.E. and Whiteman, C.H. (1992) The power problems of unit root tests in time series with autoregressive errors, Journal of Econometrics, 53, 323-343.

Devereux, M., Gregory, A., and Smith, G. (1992) Realistic cross-country consumption correlations in a two-country, equilibrium, business-cycle model, Journal of International Money and Finance, 11, 3-16.

Dickey, D. A. and Fuller, W.A. (1979) Distribution of the estimators for autoregressive time series with a unit root. Journal of the American Statistical Association, 74, 427-31.

Drobny, A. and Hall, S.G. (1989) An investigation of the long-run properties of aggregate non-durable consumers' expenditure in the United Kingdom, Economic Journal, 99, 454-460.

Duesenberry, J.S. (1952) Income, Saving and the Theory of Consumer Behavior, Harvard University Press, Cambridge Mass.

Elliot, G., Rothenberg, T. and Stock, J. H. (1996) Efficient tests of an autoregressive unit root, Econometrica, 64, 813-839.

Friedman, M. (1957) A Theory of the Consumption Function, Princeton University Press, Princeton, NJ. 
Gil-Alana, L.A. and Robinson, P.M. (2001) Testing of seasonal fractional integration in UK and Japanese consumption and income, Journal of Applied Econometrics, 16, 95-114.

Hadri, K. (2000) Testing for stationarity in heterogeneous panel data, The Econometrics Journal, 3, 148-161.

Hall, S.G. and Patterson, K.D. (1992) A systems-approach to the relationship between consumption and wealth, Applied Economics, 24, 1165-1171.

Harvey, D.I. Leybourne, S.J. and Newbold, P. (2003) How great are the great ratios?, Applied Economics, 35, 163-177.

Horioka, C.Y. (1997) A cointegration analysis of impact of the age structure of the population on the household saving rate in Japan, Review of Economics and Statistics, 79, 511-515.

Hossain, F. and Chung, P.J. (1999) Long-run implications of neoclassical growth models: Empirical evidence from Australia, New Zealand, South Korea and Taiwan, Applied Economics, 31, 1073-1082.

Im, K.S., Pesaran, M.H. and Shin, Y. (2003) Testing for unit roots in heterogeneous panels, Journal of Econometrics, 115, 53-74.

Jin, F. (1995) Cointegration of consumption and disposable income: Evidence from twelve OECD countries, Southern Economic Journal, 62, 77-88.

Kwiatkowski, D., Phillips, P.C.B., Schmidt, P. and Shin, Y. (1992) Testing the null hypothesis of stationarity against the alternative of a unit root: how sure are we that economic time series have a unit root?, Journal of Econometrics, 54, 159178. 
Lettau, M. and Ludvigson, S. (2001) Consumption, aggregate wealth, and expected stock returns, Journal of Finance, 56, 815-849.

Levin, A., Lin, C. and Chu, C. (2002) Unit Root Tests in Panel Data: Asymptotic and Finite-sample Properties, Journal of Econometrics, 108, 1-24.

Maddala, G.S. and Wu, S. (1999) A comparative study of unit root tests with panel data and a new simple test, Oxford Bulletin of Economics and Statistics, 61, 631652.

Molana, H. (1991) The time-series consumption function: error correction, random walk and the steady state, Economic Journal, 101, 382-403.

Nelson, C.R. and Plosser, C.I. (1982) Trends and random walks in macroeconomic time series: some evidence and implications, Journal of Monetary Economics, 10, $139-162$.

Ng, S. and Perron, P. (2001) Lag length selection and the construction of unit root tests with good size and power, Econometrica, 69, 1519-1554.

O'Connell, P. (1998) The overvaluation of purchasing power parity, Journal of International Economics, 44, 1-19.

Perron, P. and Ng, S. (1996) Useful modifications to some unit root tests with dependent errors and their local asymptotic properties, Review of Economic Studies, 63, 435-463.

Pesaran, M.H. (2003) A Simple Panel Unit Root Test in the Presence of CrossSection Dependence, Cambridge University, mimeo.

Phillips, P.C.B. and Perron, P. (1988) Testing for unit roots in time series, Biometrika, 75, 335-346. 
Sarantis, N. and Stewart, C. (1999) Is the consumption-income ratio stationary? Evidence from panel unit root tests, Economics Letters, 64, 309-314.

Sargan, J.D. and Bhargava, A. (1983) Testing residuals from least squares regression for being generated by the gaussian random walk, Econometrica, 51, 153-174.

Septhon, P.S. (1995) Response surface estimates of the KPSS stationarity test, Economics Letters, 47, 255-261.

Serletis, A. and Krichel, T. (1995) International evidence on the long-run implications of the neoclassical growth model, Applied Economics, 27, 205-210.

Shin, Y. and Snell, A. (2006) Mean group tests for stationarity in heterogeneous panels, The Econometrics Journal, 9, 123-158.

Slesnick, D.T. (1998) Are our data relevant to the theory? The case of aggregate consumption, Journal of Business and Economic Statistics, 16, 52-61.

Smith, L.V., Leybourne, S., Kim, T. and Newbold, P. (2004) More powerful panel data unit root tests with an application to the mean reversion in real exchange rates, Journal of Applied Econometrics, 19, 147-170.

Strauss, J. and Yigit, T. (2003) Shortfalls of panel unit root testing, Economics Letters, 81, 309-313.

Taylor, M. P. and Sarno, L. (1998) The behavior of real exchange rates during the post-Bretton Woods period, Journal of International Economics, 46, 281-312.

Urgern-Stemberg, T.V. (1986) Inflation and the consumption function, Weltwirtschaftliches Archiv, 122, 741-744. 


\section{TABLES}

Table 1: Univariate unit root tests. Consumption-income ratio. OECD countries. 1960-2005. Specification with trend.

\begin{tabular}{llllllll}
\hline \hline COUNTRY & $k$ & $M Z_{\alpha}^{G L S}$ & $M Z_{t}^{G L S}$ & $M S B^{G L S}$ & $P_{T}^{G L S}$ & $A D F^{G L S}$ & $\eta_{i}$ \\
\hline Australia & 2 & -7.089 & -1.818 & 0.256 & 12.574 & -1.890 & $0.123^{*}$ \\
Austria & 0 & -3.337 & -1.064 & 0.319 & 25.412 & -1.289 & $0.157^{* *}$ \\
Belgium & 0 & -6.347 & -1.710 & 0.269 & 16.095 & -2.003 & 0.107 \\
Canada & 1 & -10.770 & -2.295 & 0.213 & 8.265 & -2.433 & 0.109 \\
Switzerland & 2 & -5.081 & -1.547 & 0.304 & 17.077 & -1.628 & $0.144^{*}$ \\
Germany & 0 & -4.108 & -1.156 & 0.281 & 20.405 & -1.332 & 0.099 \\
Denmark & 0 & -11.117 & -2.246 & 0.202 & 8.667 & $-2.657^{*}$ & 0.113 \\
Spain & 0 & -4.572 & -1.468 & 0.321 & 19.299 & -1.577 & 0.104 \\
Finland & 0 & -3.287 & -1.193 & 0.363 & 31.439 & -1.557 & $0.136^{*}$ \\
France & 0 & -7.817 & -1.968 & 0.252 & 14.018 & -2.392 & $0.133^{*}$ \\
United Kingdom & 6 & -4.819 & -1.495 & 0.310 & 20.838 & -1.448 & 0.106 \\
Greece & 0 & -5.172 & -1.567 & 0.303 & 19.622 & -1.833 & 0.095 \\
Ireland & 0 & -10.128 & -2.187 & 0.216 & 9.534 & -2.568 & 0.098 \\
Iceland & 3 & -4.412 & -1.485 & 0.337 & 23.494 & -1.567 & 0.120 \\
Italy & 3 & -4.123 & -1.348 & 0.327 & 23.742 & -1.294 & $0.144^{*}$ \\
Japan & 2 & -8.025 & -1.998 & 0.249 & 11.993 & -2.034 & $0.130^{*}$ \\
Luxembourg & 0 & -1.037 & -0.577 & 0.557 & 68.869 & -0.876 & $0.155^{* *}$ \\
Netherlands & 1 & -2.602 & -1.090 & 0.419 & 41.288 & -1.292 & $0.145^{*}$ \\
Norway & 0 & -1.553 & -0.506 & 0.326 & 27.914 & -0.516 & 0.094 \\
New Zealand & 4 & -6.935 & -1.785 & 0.257 & 12.718 & -1.824 & 0.110 \\
Portugal & 0 & -8.252 & -1.983 & 0.240 & 10.950 & -2.228 & 0.085 \\
Sweden & 8 & -2.070 & -1.014 & 0.490 & 46.193 & -1.086 & 0.120 \\
United States & 0 & -4.848 & -1.556 & 0.321 & 18.337 & -1.670 & 0.118 \\
\hline No: $k$ is $t h$ & & 0.196 &
\end{tabular}

Note: $k$ is the degree of augmentation of the ADF regression and is selected with MAIC (for instance $k=4$ implies an $\mathrm{AR}(5)$ process). The $1 \%, 5 \%$ and $10 \%$ critical values for the $M Z_{\alpha}^{G L S}$ test are $-23.8,-17.3$ and -14.2 , respectively. The $1 \%, 5 \%$ and $10 \%$ critical values for the $M Z_{t}^{G L S}$ test are $-3.42,-2.91$ and -2.62 , respectively. The $1 \%, 5 \%$ and $10 \%$ critical values for the $M S B^{G L S}$ test are $0.143,0.168$ and 0.185 , respectively. The $1 \%, 5 \%$ and $10 \%$ critical values for the $P_{T}^{G L S}$ test are 4.03, 5.48 and 6.67 , respectively. The $1 \%, 5 \%$ and $10 \%$ critical values for the $A D F^{G L S}$ test are $-3.42,-2.91$ and -2.62 , respectively. The $1 \%, 5 \%$ and $10 \%$ finite-sample critical values for the KPSS test $\left(\eta_{i}\right)$ are $0.213,0.149,0.121$, respectively, for $\mathrm{T}=50$ (see Sephton, 1995). ${ }^{* * *}, * *$ and $*$ imply rejection of the null hypothesis at $1 \%, 5 \%$ and $10 \%$, respectively. 
Table 2: Panel unit root test of Smith et al. (2004) and Pesaran (2003). Consumption-income ratio. OECD countries. 1960-2005.

\begin{tabular}{lll|ll}
\hline \hline & \multicolumn{2}{c}{ NO TREND } & \multicolumn{2}{c}{ TREND } \\
\hline$\Psi_{\bar{t}}$ & Tests & p-value & Tests & p-value \\
$\Psi_{\text {Max }}$ & -1.648 & 0.181 & -2.181 & 0.303 \\
$\Psi_{L M}$ & -0.983 & 0.385 & -1.653 & 0.525 \\
$\Psi_{\text {Min }}$ & 4.034 & 0.140 & 4.791 & 0.435 \\
$\Psi_{W S}$ & 2.430 & 0.160 & 3.558 & 0.323 \\
$C I P S$ & -1.165 & 0.451 & -2.010 & 0.589 \\
$C Z$ & -1.639 & & -2.412 & \\
\hline
\end{tabular}

Notes: The bootstrap p-values for the five panel unit root tests of Smith et al. (2004) are computed employing 20,000 bootstrap replications and defining a block size equal to 30 . The maximum lag order is set to 8. The panel unit root tests of Pesaran (2003) are computed with an optimal lag truncation of three. The $1 \%, 5 \%$ and $10 \%$ critical values for the CIPS test (CZ test) are $-2.36,-2.20$ and $-2.11(-2.87,-2.04$ and -1.58$)$, for the specification without trends. The $1 \%, 5 \%$ and $10 \%$ critical values for the CIPS test $(C Z$ test) are $-2.85,-2.71$ and $-2.63(-2.67,-1.85$ and -1.41$)$, for the specification with trends. These critical values are computed for $\mathrm{T}=50$ and $\mathrm{N}=20 . * * * * *$ and $*$ imply rejection of the null hypothesis at $1 \%, 5 \%$ and $10 \%$, respectively.

Table 3: Panel stationarity test of Hadri (2000)

Consumption-income ratio. OECD countries. 1960-2005.

\begin{tabular}{|c|c|c|c|c|c|c|c|c|}
\hline \multicolumn{9}{|c|}{ Panel A: Panel KPSS test assuming cross-sectional independence } \\
\hline & \multicolumn{4}{|c|}{ NO TREND } & \multicolumn{3}{|c|}{ TREND } & \\
\hline & Test & & p-value & & Test & & alue & \\
\hline LM (Homogeneous) & $9.768^{* * *}$ & & 0.000 & & $7.052 * * *$ & & & \\
\hline LM (Heterogeneous) & $6.889^{* * *}$ & & 0.000 & & $6.060 * * *$ & & & \\
\hline \multicolumn{9}{|c|}{ Panel B: Bootstrap critical values (assuming cross-section dependence) } \\
\hline & $10 \%$ & $5 \%$ & $2.5 \%$ & $1 \%$ & $10 \%$ & $5 \%$ & $2.5 \%$ & $1 \%$ \\
\hline LM (Homogeneous) & 3.950 & 5.986 & 7.953 & 10.643 & 3.924 & 5.339 & 6.746 & 8.550 \\
\hline LM (Heterogeneous) & 3.199 & 4.649 & 6.098 & 7.764 & 3.163 & 4.269 & 5.374 & 6.834 \\
\hline
\end{tabular}

Notes: The bootstrap critical values for Hadri's test are computed employing 20,000 bootstrap replications. LM(Homogeneous) and LM(Heterogeneous) denote the panel KPSS test of Hadri (2000) for the case of homogeneity and heterogeneity in the estimation of the long-run variance, respectively. ${ }^{* * *}, * *$ and $*$ imply rejection of the null hypothesis at $1 \%$, $5 \%$ and $10 \%$, respectively. 